\title{
Labeling of Agri-food Products in Albanian Agriculture Context
}

\author{
Edlira Llazo \\ PhD, University "A.Moisiu", Durres, Albania \\ Elton Noti \\ Prof. Assoc., University "A.Moisiu", Durres, Albania
}

Doi: 10.1515/ajis-2017-0013

\begin{abstract}
Albanian agriculture and especially the albanian farmer are experiencing a difficult situation with the ability to compete in the market.Albanian agriculture is a very important sector of the economy but with little contribution in the economic growth, due to a misorientation in the market of the albanian production. This study aims to adress some concerns and to open a discussion linked to the use of labelling as an instrument that would orient the albanian agriculture to a product with an added value and to make the albanian product a competitor even for the global market, based on the wide literature and on the experience of the more developed countires also referring to primary data.
\end{abstract}

Keywords: agriculture, credence attributes, consumer, labeling

\section{Introduction}

Today agricultural producers and food enterprises have not only to anticipate the slow growth in food demand, but also to cope with severe competition existing between them, due to the globalised economy. Thus the efforts of food businesses move along two parallel directions. One is aiming to increase the quantity to be consumed by offering consumers new products to cover their needs, while the other is moving to the generation of value added for certain products that have special characteristics, that attract consumers and add to their satisfaction.

Agriculture in Albania is one of the most important sectors of economy even though today it doesn't contribute enough in the GDP. The difficult transition of this sector in the process of transformation to a free market economy has been very long. The national production is still low and is facing some big difficulties in finding the way to the market. The albanian farm is too small and the costs of production are still high compared to the region. This way the national production faces some big competition from imported products. The need to identify the competitive advantages of the sector and to explore towards a product with an added value is evident.

The handling of the topic linked to labeling aims to contribute in getting to know better the marketing methonds that can be useful to the marketing of the farm's products. First of all, the study aims to expand the actual knowledge of the farmer about labeling as an useful instrument to increase the value of their products. The use of different labels that are today in the global market can be an advantage for the albanian products.

This study aims to explore the costumers's attitude for these credence atributes, how they affect the process of buying. The sensibility that the albanian consumer appeared to these labels will be used as an orientation for the albanian farmers to orientate them to the market. This study also aims to give information even for the governmental institutions that must support the farmers with their public policies. 


\section{Literature Review}

The creation of value is today a key point in being competitive in the market of agricultural products, which today is facing a new developing dinamics.

"Under these new conditions prevailing in food markets and the requirementsgenerated, "quality" has been accepted as a strategic element of marketing that helps sustain or improve the position of an actor in the food supply chain. According to (van Trijp et al., 1997) in the competitive environment in agricultural markets quality differentiation will be made through an important strategy. The "quality" aspect is also viewed as a promising tool that can generate more valueadded for a product" (Scuras and Vacrou,2002). There are different points of view of the concept of quality, such quote is said by The Scottish Food Strategy Group (1993)

... a quality food and drink product is one which is differentiated in a positive manner by reason of one or more of these features from the standard product, is recognized as such by the consumer, and can therefore command a market benefit if it is effectively marketed.

Sylvander (1993) has listed in his studies some subjective and objective indicators, as below. These are :

- Price

- Product appearance(including packaging)

- Certification(by state, professional organization or external body)

- Specifications

- Individual skill of the buyer

- Individual or collective trade mark

However, there isn't an official definition from The Europian Commision about the quality because there are different opinions from consumers about what can be called qualitative. But in each case quality is linked to some attributes of the product that from a consumer's point of view give added value. Today in the global market exist such terms as: "local", "eco-friendly", "place of origin". They aim to expose credence attributes that are considered by the consumer in his decisions. There are different studies that show that for agricultural products, the place of origin of the product is very important (BeÂrand and Marchenay, 1995) and there is a strong connection with the perception of the consumer about quality(Verlegh and Steenkamp,1999).

The OECD (1995) in the report "Niche markets as rural development strategy" states that quality is a matter of perceptions of the consumer and that quality is increasingly being defined as something that custom produced as opposed to mass produced.

The European Commission recognizes the difficulty of providing a coherent definition for quality in its official Web page for agricultural quality products and draws upon certain elements that build quality, like food safety, environmental production methods, nutritional value and product characteristics, together with region of origin and tradition in the production methods used (European Commission, 2001).

The quality guarantee is based on a variety of elements and several instruments that can be used to implement any adopted scheme. But the most important instrument is the legislative framework that supports the quality attributes and appropriate labeling that provides for the verification of the scheme and its subsequent recognition by both consumer and market.

\section{Labbelling and Albanian Context}

Internationally, labeling policy is least settled and developed in the areas of food safety and processing, as well as origin, while approaches to nutrition labeling are more uniform (Caswell, 1997). In EU two regulations have been introduced in 1992 (Reg. 2081/92 and 2082/92) on certificates of specific characteristics for agricultural products and foodstuffs. The aim was to promote the concept of regionally produced products that include the characteristics of quality, tradition and ancient production methods. The two regulations developed three distinct categories of regionally identified products, namely PDO (Products of Denominated Origin), PGI (Product of 
Geographic Indication) and GTS (Guaranteed Traditional Speciality) products.

These products guarantee a special link with their territory, either because they are explicitly produced there, or due to other relational elements with a specific area and the local conditions prevailing in there (special recipes, typicality, etc.). The characteristics of the production area or the region of origin for quality products have been identified as important ones and have been used widely by OECD (1995).

The LEADER II (executed for the period 1994-1999) had financed projects that valorized the concept of quality and allowed for innovative promotion actions. The importance of these actions is growing, as the option for providing further measures for the promotion of local products has been reinforced by EC Reg. 1257/99.

Of course that the adaptation of these politics has helped the countries inside the EU to make actual plans to support and promote local and qualitative products. Different authors look at these instruments as a good strategy for small farms and also as a way to develop rural areas.

Albanian agriculture is very fragmented in most parts dominated by very small farms, intensive in human work in means of survival. On the other hand, Albanian landscape and the land's geography provide a large biodiversity and high-quality products that are linked to the territory where they come from. The agricultural product when it enters the market is neither packaged nor standardized and does not have the minimal information for the consumer about its special attributes. This makes the local production ,even in some cases of a better quality, finds it very hard to compete the imported products. Also the lack of standards or necessary certifications makes it even harder the export as Albanian is not part of the EU.

\section{Study Objectives}

The main purpose of this study was to obtain information that could help farmers increase the profitability of their operations and improve the likelihood that they would continue farming. Considering the absolute lack of literature and scientific research in Albania that is responsible for the agricultural economy and especially for the labelling politics, this study aims to open a discussion and to invite other researchers to explore in this field. It also aims to help farmers to be market oriented and to give them useful information about costumer perceptions for the attributes of farm product. This paper is based on a literature review and primary data through which we can understand the levels of satisfaction of the consumers with the products they buy, which are the main criteria that they validate and what extra information would they want about the special attributes of the products. The study aims to help the farmers to orient better to the market and also to draw attention of other researchers about this topic that is so important in Albania.

\subsection{Procedure}

Primary data for this study was obtained through a face to face survey of 150 Albanian costumers who live in Tirana and Durres. This is the most populated area, who live almost $1 / 3$ of the Albanian population. We conducted the survey between 15 October and 30 November, 2015. The survey instrument contained questions related to respondents' behaviour, attitudes. A sample of households was selected randomly, and the interviews were made near some of the biggest agricultural markets where the consumers buy these kinds of products to be more sure that the respondents were the primary food shopper for the household.

\section{Results and Discussion}

The following pages contain tables and summaries of the survey responses for selected questions. The information give the answers about some important questions to understand the costumer perception and behaviour towards some credence attributes of products.

Are you content with the agricultural products that you consume? 


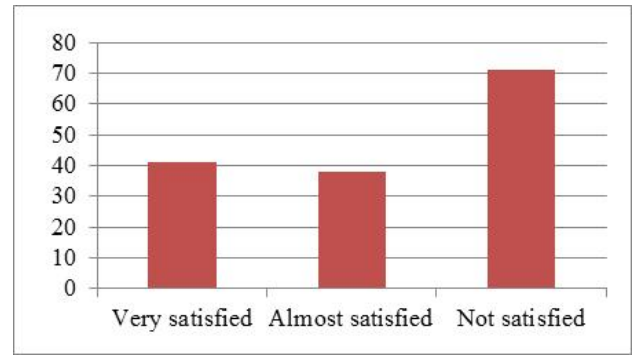

Which of the following aspects are the most concerning for you?

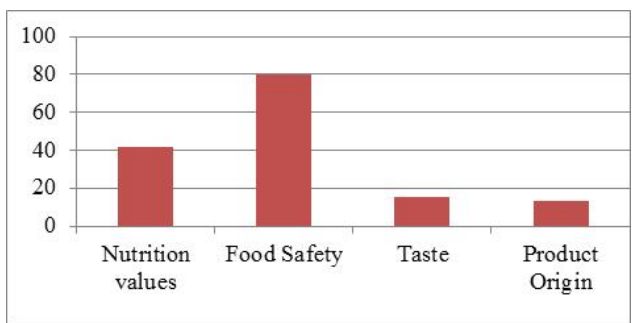

When buying agricultural products, how important is for you the information that you receive about the method it is produced?

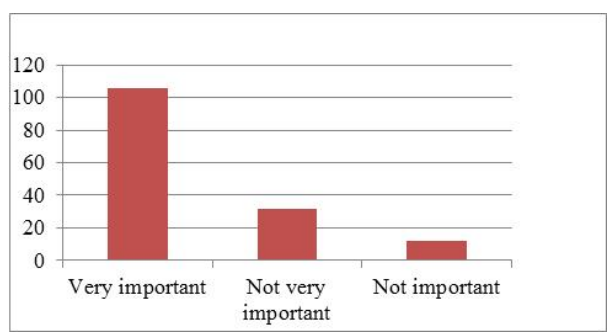

Order some of the possible certifications that can be put to an agricultural product according to the characteristics of the product. For which of these certifications would you show more interest?

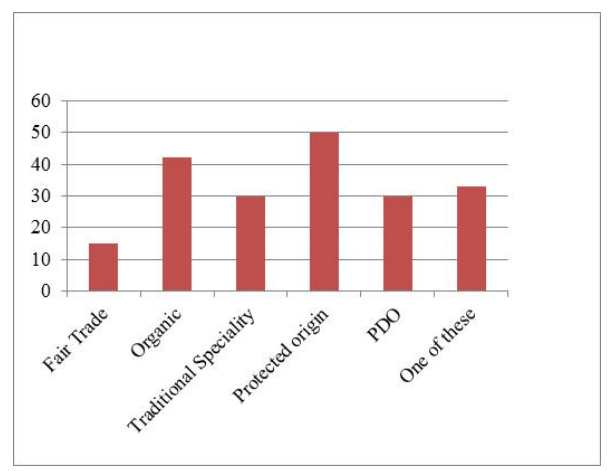

From the results taken it is shown a big concern from the Albanian consumer for the agricultural products they use, there is a dissatisfaction linked to many aspects from which the most important 
is food safety and lack of information about the standarts of the product. On the other hand the Albanian farmer is very small, high costs of production, limited amount of land, lack of standartization and certification of products makes his position in the national and global market very hard. Albania is not yet a country of the EU and the farmer's difficulties to get to the europian market are much bigger. The positive side is that the Albanian agriculture has a massive opportunity to compete with the product with added value. Albanian farms produce high quality products but due to a lack of a certification system or a labeling system to expose these product's credence attributes. This advantage remains unused.

Although there is a positive experience of the Albanian companies that assisted by international helping programs have managed to get a certification a Global Gap and have reached the global market. Agrocon, is one of these Albanian companies and supplies the local market but also exports to Czech Republic, Slovenia and Croatia. It also eyes Western Europe countries. Agrocon is among the first companies to receive Global Gap certification through USAID's B-REDI project for international certification. Global Gap is mandatory for every producer who wants to enter EU markets .

A national labeling system with several easily understood grades or levels would make possible the use of the national market's opportunities which expresses a high demand for national products and that would allow consumers and retailers to purchase products of known standard. Consumer confidence in the labeling system would, in turn, enhance marketing opportunities for high quality products.

\section{Conclusions}

Our study shows that the Albanian consumer is not content with the agricultural products and that has a rising concern about the food safety and the information that he gets in the market. On the other hand, we have a difficult situation of the small Albanian farmers who haven't found yet the path to show in the inner and outer market their competitive advantages.

This situation needs a fast answer and that is linked to a labeling system which will help the consumers in their choices by receiving information about the products. Also such system will help the diversification of the market and also would help the Albanian agricultural products be competitive in foreign markets.Certain regions in Albania a high reputation in the production of their specific products and an origin label would help them compete with the product with added value.

Region identification promotes the idea not only that there is a price differentiation between producing origins, but also that there exist intellectual property rights that govern significant productions, which stake their reputation on their origin. The concept underlying these efforts is to promote a great variety of these products as generic ones, through well-designed promotional activities and to create an umbrella for this diversified production.

\section{References}

BeÂrand, L. and Marchenay, P. (1995), “'Lieux, temps et preuves: la construction sociale des produits de terroir", Terrain, Vol. 24, p. 153-64.

Caswell, J.A. (1997), "Uses of food labelling regulations", The OECD Report on Regulatory Reform, Vol. I: Sectoral Studies, OECD, Paris.

European Commission (2001), "Food quality", Web page available at: europa.eu.int/comm./agriculture/foodqual /quali_en.htm (last accessed at 20 December 2001).

LEADER European Observatory (2000), "Marketing local products. Short and long distributions channels", Rural Innovation, Dossier No 7, Brussels.

OECD(1995),"Niche Markers as a Rural Development Strategy", Paris.

Skuras, D., and Vakrou, A., (2002) " Consumers' willingness to pay for origin labelled wine. A Greek case study", British Food Journal, Vol.104 No.11, pp.898-912

Scottish Food Strategy Group (1993), ScotlandMeans Quality, SFSG, Edinburgh

Sylvander, B., (1993).Quality Products; an Opportunity for Rural Areas.,LEADER Magazine, Spring 3.

Van Trijp, H.J.C.M., Steenkamp, J-B.E.M. and Candel, M.J.J.M. (1997), “Quality labeling as instrument to create product equity; the case of IKB in The Netherlands", Agricultural Marketing and Consumer Behavior in a Changing World, pp.201-215 
Verlegh, P.W.J. and Steenkamp, J-B.E.M. (1999), “A review and meta-analysis of country-of origin research", Journal of Economic Psychology, Vol. 20, pp. 521-46. 